\title{
Ratio legis kewajiban untuk menjaga dan menghormati norma agama berdasarkan Undang-Undang Kepariwisataan
}

\author{
Dwi Aryanti Ramadhani ${ }^{1}$, Aji Lukman Ibrahim ${ }^{2}$, Rianda Dirkareshza ${ }^{3}$.
}

${ }^{1}$ Dwi Aryanti Ramadhani; Fakultas Hukum Universitas Pembangunan Nasional Veteran Jakarta; Jl. RS. Fatmawati Raya, Pd. Labu, Kec. Cilandak, Kota Depok; 12450; Jawa Barat; Indonesia.

${ }^{2}$ Aji Lukman Ibrahim; Fakultas Hukum Universitas Pembangunan Nasional Veteran Jakarta; Jl. RS. Fatmawati Raya, Pd. Labu, Kec. Cilandak, Kota Depok; 12450; Jawa Barat; Indonesia.

${ }^{3}$ Rianda Dirkareshza; Fakultas Hukum Universitas Pembangunan Nasional Veteran Jakarta; Jl. RS. Fatmawati Raya, Pd. Labu, Kec. Cilandak, Kota Depok; 12450; Jawa Barat; Indonesia.

\begin{tabular}{l} 
A R T I C L E I N F O \\
\hline Article history: \\
Received 2020-04-12 \\
Received in revised form \\
2021-06-25 \\
Accepted 2021-08-01 \\
\hline Kata kunci: \\
Ratio Legis; Wisatawan; \\
Norma Agama. \\
Keywords: \\
RatioLegis; Tourist; Religious \\
Norms.
\end{tabular}

DOI: $h$ ttps://doi.org/10.26905/ idjch.v12i2.5353.

\section{How to cite item:}

Ramadhani, DA., Ibrahim, AL., Dirkareshza, R. (2021). Ratio legis kewajiban untuk menjaga dan menghormati norma agama berdasarkan Undang-Undang Kepariwisataan.Jurnal Cakrawala Hukum, 12(2), 159-167. doi: 10.26905/idjch.v12i2.5353.

\begin{abstract}
Abstrak
Kabupaten Pandeglang menjadi wilayah yang terdampak tsunami di Selat Sunda. Untuk membangun kembali kepariwisataan, perlu disusun perencanaan secara terpadu dengan menyusun regulasi tentang kepariwisataan. Penelitian ini bertujuan untuk mengetahui Ratio Legis kewajiban untuk menjaga dan menghormati norma agama bagi wisatawan dalam undang-undang kepariwisataan serta mengetahui bentuk perlindungan hokum bagi wisatawan yang melanggar norma agama ditempat wisata. Metode penelitian yang digunakan berupa penelitian hukum normatif yang dilengkapi wawancara dengan kepala desa wisata di kabupaten Pandeglang. Hasil penelitian menunjukkan bahwa ratio legis kewajiban untuk menjaga dan menghormati norma agama, adat istiadat, budaya, dan nilai-nilai yang hidup dalam masyarakat bagi wisatawan adalah agar budaya setempat tidak terkontaminasi budaya asing yang dibawa oleh para wisatawan. Kemudian sanksi yang diterapkan hanya berupa teguran kurang sepadan dengan kerugian yang ditimbulkan.
\end{abstract}

\section{Abstract}

Pandeglang Regency is a tsunami-affected area in the Sunda Strait. In order to rebuild tourism, it is necessary to formulate an integrated planning by compiling regulations on tourism. This study aims to determine the Ratio Legis obligation to maintain and respect religious norms for tourists in tourism laws and to find out the form of legal protection for tourists who violate religious norms in tourist attractions. The research method used is in the form of normative legal research complemented by interviews with the head of the tourism village in Pandeglang district.

*Dwi Aryanti Ramadhani.

E-mail address: dwiaryanti@upnvj.ac.id.

C 2021 Jurnal Cakrawala Hukum - University of Merdeka Malang. 


\section{Jurnal Cakrawala Hukum, Volume 12 No. 2 Agustus 2021 \\ ISSN PRINT 2356-4962 ISSN ONLINE 2598-6538}

The results showed that the ratio legis obligation to maintain and respect religious norms, customs, culture, and values that live in the community for tourists so that the local culture is not contaminated with foreign cultures brought by tourists. Then the sanctions applied only in the form of a warning are not commensurate with the losses incurred.

\section{Latar Belakang}

Pariwisata adalah kegiatan wisata yang didukung berbagai fasilitas serta layanan yang disediakan oleh masyarakat, pengusaha, Pemerintah, dan Pemerintah Daerah. (Indonesia, 2009, p. Pasal 1 Angka ke-3) Pariwisata salah satu sektor yang menjanjikan untuk meningkatkan pertumbuhan ekonomi Indonesia, membantu membuka investasi swasta, menambah ekspor, dan memandu investasi infrastruktur, (Hamzana, 2018) meningkatkan citra Indonesia, meningkatkan kesejahteraan masyarakat lokal, serta memberikan perluasan kesempatan kerja. (Bappenas, 2005)

Sektor pariwisata diharapkan menjadi sektor yang mampumemimpin dalam pembangunan, maka pengkajian yang lebih intensif dan menyeluruh perludilakukan rnengingat sektor-sektor pembangunan lainnya yang secara langsung maupun tidak langsung besar pengaruhnya dalam pengembangan pariwisata (Yanti \& Hadya, 2018)

Diperlukan regulasi terkait hal-hal yang dapat mendukung tercapainya tujuan pembangunan pariwisata dengan memperhatikan potensi kekhasan yang dimiliki oleh tiap-tiap daerah diseluruh wilayah Indonesia. (Mufida, 2019) Penelitian ini berfokus pada pariwisata di Provinsi Banten yang secara administratif, terbagi atas 4 Kabupaten, 4 Kota 4 Kabupaten, 4 Kota, 154 Kecamatan, 262 Kelurahan dan 1.273 Desa, dengan luas $9.160,70 \mathrm{Km}^{2}$. Jumlah penduduknya sebanyak 12.548.986 Jiwa. (Banten, n.d.) Suku Bangsa Sunda dan Baduya, Agama Islam, Protestan, Katolik, Budha, Hindu, Konghucu. (Banten, 2020)

Provinsi Banten sebagai salah satu provinsi di Indonesia memiliki kekayaan alam dan budaya yang mampumenarik wisatawan untuk datang. Provinsi Banten Senantiasa mengembangkan Kawasan wisata yang berpegang pada prinsip pariwisata berkelanjutan. (Kristiana \& Stephanie Thedora M, 2016) Kabupaten Pandeglang dipilih karena memiliki potensi pariwisata yang relative tinggi dibandingkan dengan kabupaten lain di Provinsi Banten.Wilayahnya juga mencakup Pulau Panaitan, serta sejumlah pulau-pulau kecildi Samudra Hindia, termasuk Pulau Delidan Pulau Tinjil. (Pandeglang, 2019)

Semenanjung Ujung Kulon merupakan ujung paling barat Pulau Jawa, dimana terdapat suaka margasatwa tempat perlindungan hewan Badak bercula satu yang kini hamper punah. Potensi pariwisata yang ada di Kabupaten Pandeglang adalah: Sumber Daya Air Panas Cisolong; Situ Cikedal; Pantai Carita; Kolam Renang Alam Cikoromoy; Wisata Pantai Bama; Wisata Pantai Bama; Wisata Tanjung Lesung; dan Taman Nasional Ujung Kulon. (Pandeglang, 2019)

Provinsi Banten sebagai salah satu daerah penyangga antara pulau Jawa dan Sumatera dalam strategi MP3EI 2011-2025 tentunya memiliki peran strategis seiring dengan terbitnyaPeraturan Pemerintah (PP) No. 26 tahun 2012 Untuk bisa menjabarkan dan menterjemahkan kebijakan pemerintah Provinsi Banten yang sudah memasukan pembangunan Kawasan Ekonomi Khusus (KEK) Tanjung Lesung pada RPJMD Provinsi Banten tahun 2012-2017, dalam rencana pemerintah daerah, utamanya dalam menghadapi dampak multiplier, keberadaan humas pemerintah Provinsi Banten menjadi penting artinya dalam membuat suatu perencanaan strategi kehumasan dalam hal pengembangan KEK Pariwisata Tanjung 


\section{Ratio legis kewajiban untuk menjaga dan menghormati norma agama berdasarkan Undang-Undang Kepariwisataan \\ Dwi Aryanti Ramadhani, Aji Lukman Ibrahim, Rianda Dirkareshza}

Lesung. Humas bukan saja sekedar berada padawilayah "seremoni" semata, (Mukhroman \& Gumelar, 2013)

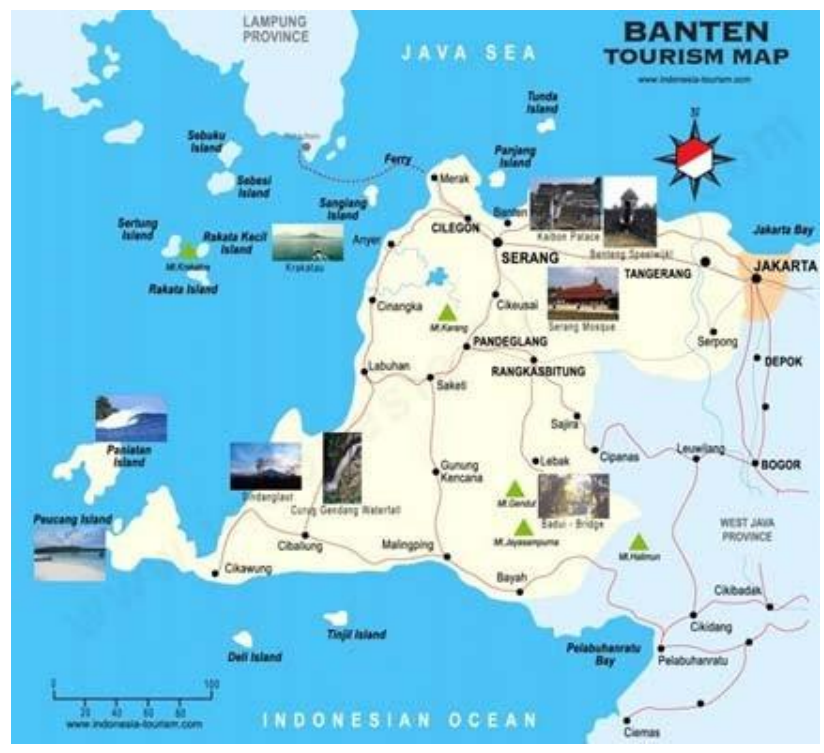

Gambar Peta PariwisataProvinsi Banten

(Pemerintah Daerah Provinsi Banten, 2020)

Salah satu Rencana Pembangunan Jangka Menengah Daerah (RPJMD) Kabupaten Pandeglang tahun 2016-2021 adalah modernisasi pengelolaan potensi pariwisata, maka dalam hal ini perlu dikaji pengaturan kepariwisataan pasca bencana Tsunami yang melanda akhir tahun 2018. Kabupaten Pandeglang menjadi salah satu wilayah yang terdampak Tsunami di Selat Sunda. Berdasarkan laporan Badan Meteorologi, Klimatologi, dan Geofisika (BMKG) bahwaTsunami yang terjadi di Selat Sunda bukan disebabkan gempa bumi tektonik, melainkan erupsi Gunung Anak Krakatau. (Arnani, 2018) Wilayah terdampak tsunami Selat Sunda terparah adalah Kabupaten Pandeglang, meliputi 10 kecamatan, yaitu: Carita, Panimbang, Sumur, Labuan, Menes, Cibaliung, Jibut, Cimanggu, Pagelaran, dan Cigeulis. (Defianti, 2018) Sejumlah tempat wisata di Pandeglang rusak parah, diantaranya Tanjung Lesung, Bantu Hideung di Kecamatan Panimbang, Pantai Carita di Kecamatan Carita, Pantai Pasir Putih, dan yang lainnya di Kecamatan Sumur. (Antara, 2018) Pasal 5 Undang-undang Nomor 10 Tahun 2009 tentang Kepariwisataan (UU Kepariwisataan) mengatur mengenai prinsip-prinsip penyelenggaraan kepariwisataan.

Selanjtnya, Pasal 25 UU Kepariwisataan, mengatur tentang kewajiban wisatawan. Kewajiban yang pertama dalam pasal tersebut adalah kewajiban untuk menjaga dan menghormati norma agama, adat istiadat, budaya, dan nilai-nilai yang hidup dalam masyarakat setempat. Namun, kewajiban tersebut tidak diikuti dengan pengaturan tentang sanksi yang tegas terhadap pelanggarannya. Sanksi terhadap pelanggaran Pasal 25 diatur dalam Pasal 62-63 UU Kepariwisataan. Sanksi yang diberikan berupa sanksi administrative yang sangat ringan, yaitu teguran.

Kajian Potensi Pariwisata Perkotaan (Urban Tourism) Sebagai Daya Tarik Wisata kota Mataram Provinsi Nusa Tenggara Barat adalah salah satu tulisan yang membahas kepariwisataan. Tujuan penelitian ini yaitu mengkaji pariwisata perkotaan (urban tourism) sebagai daya tarik wisata di Kota Mataram. Hasil analisis yang dilakukan potensi wisata perkotaan (urban tourism) di Kota mataram yaitu: kantor gubernur nusa tenggara barat, taman sangkareang, taman udayana, taman selagalas, taman mayura, monumen bahari mataram, monumen bumi gora, museum negeri nusa tenggara barat, kawasan wisata kuliner rembiga, masjid raya hubbul wathan islamic centre, pura meru, makam bintaro, makam van Ham, makan loang baloq, lombok epicentrum mall (LEM), mataram mall, transmart carrefour mataram, mataram craft centre (MCC), pasar cakranegara, arena buah cakranegara, tempat karaoke, kawasan kota tua, kawasan pantai loang baloq, pantai gading, pantai ampenan, kerajinan cukli di rungkang jangkuk kota mataram, kemilau mutiara sekarbela di kampung sekarbela.

Sedangkan ketersediaan komponen produk pariwisata dalam di kota mataram telah tersedia 


\section{Jurnal Cakrawala Hukum, Volume 12 No. 2 Agustus 2021}

ISSN PRINT 2356-4962 ISSN ONLINE 2598-6538

dan memadai, seperti keberadaan terminal bus antar kota-antar provinsi, kondisi jalan yang baik, tersedianya bandara internasional serta adanya instansi pemerintah dibidang kepariwisataan yang dapat mengelola dan mengembangkan daya tarik wisata di Kota Mataram. Berdasarkan hasil tersebut, pemerintah daerah dan swasta dapat bersinergi dalam membangun pariwisata perkotaan di kota mataram. Selain itu kepada pengelola daya tarik wisata dapat memberikan edukasi kepada pengunjung untuk selalu menjaga kebersihan tempat yang dikunjungi.(Kurniansah, 2018)

Dampak Keberadaan Pariwisata Religi terhadap Perkembangan Ekonomi Masyarakat Cirebon. Al-Amwal: Jurnal Ekonomi dan Perbankan Syari'ah adalah penelitian mengenai pariwisata yang bertujuan untuk mengetahui peluang usaha masyarakat sekitar obyek wisata religi di Kota Cirebon, peningkatan pendapatan yang didapat oleh pedagang kawasan obyek wisata religi di Kota Cirebon, penyerapan tenaga kerja di daerah kawasan obyek wisata religi di Kota Cirebon. Hasil penelitian menunjukkan bahwa adanya obyek wisata religi memiliki pengaruh yang sangat besar dalam pengembangan usaha untuk meningkatkan ekonomi masyarakat dan peningkatan ekonomi atau pengahasilan ini akan terasa cukup signifikan apabila ada moment-moment yang dilakukan oleh pihak pengelola pariwisata, dampak yang cukup signifikan lainya bagi kehidupan masyarakat Cirebon adalah dapat terciptanya lapangan pekerjaan baru untuk warga di sekitar tempat wisata baik untuk keluarga maupun untuk orang lain.(Djuwita et al., 2017)

Pengembangan Pariwisata Bahari (Studi Deskriptif Pada Pelaku Pengembangan Pariwisata Bahari Pantai Watukarung Desa Watukarung Kecamatan Pringkuku Kabupaten Pacitan). Jurnal perbandingan terakhir mengenai kebaruan dari artikel ini. Penelitian ini bertujuan untuk mengetahui potensi wisata bahari, faktor pendukung dan pembatas, strategi, serta dampak pengembangan pariwisata di pesisir Watukarung di Desa Watukarang Kecamatan Prapuku Kabupaten Pacitan Jawa Timur. Hasil penelitian ini menunjukkan bahwa potensi wisata potensi alam berupa bentuk pantai pesisir laut tertentu Watukarung; potensi sosial yaitu sikap pilar dan komunitas royong; po- tensi ekonomi yang merupakan mata pencaharian masyarakat sebagai nelayan dan usaha pariwisata dalam bentuk warung makan, homestay, laundry, dan pembuatan souvenir; dan potensi budaya adalah karawitan, ketoprak, rontek, dan hadrah. (Sayogi \& Dermatoto, 2009)

Penelitian dengan tema pariwisata memang telah banyak dilakukan, diantaranya seperti yang telah penulis uraikan di atas. Dari kelima penelitian terdahulu, tidak ada penelitian yang mempunyai tema serupa dengan penelitian ini. Maka dari itu penelitian ini merupakan penelitian yang berbeda dari penelitian yang sudah pernah ada sebelumnya.

Penelitian ini bertujuan untuk mengetahui ratio legis kewajiban wisatawan menjaga dan menghormati norma agama, adat istiadat, budaya dan nilai-nilai yang hidup di masyarakat dalam undang-undang kepariwisataan dan untuk mengetahui sanksi yang seharusnya terhadap wisatawan yang melanggar norma agama, adat istiadat, budaya, dan nilai-nilai yang hidup dalam masyarakat ditempat wisata.

\section{Metode}

Metode penelitian yang digunakan berupa penelitian hukum normatif yang dilengkapi wawancara yaitu penelitian kepustkaan yang menggunakan data sekunderya itu bahan hukum primer berupa peraturan perundang-undangan, bahan hukum sekunder berupa buku dan jurnal terkait dengan tema penelitian dan bahan hukum tersier berupa kamus dan Naskah Akademis.

Teknik pengumpulan data dilakukan dengan cara studi dokumentasi terhadap data sekunder yang diperoleh. Untuk melengkapi data, penulis 


\section{Ratio legis kewajiban untuk menjaga dan menghormati norma agama berdasarkan Undang-Undang Kepariwisataan \\ Dwi Aryanti Ramadhani, Aji Lukman Ibrahim, Rianda Dirkareshza}

juga melakukan wawancara dengan salah satu Kepala Desa, di desa wisata di kabupaten Pandeglang. Data primer dan sekunder yang telah dikumpulkan dianalisis secara kualitatif, kemudian disajikan secara deskriptif-analitis-preskriptif. Teknik penarikan kesimpulan dilakukan secara Induktif.

\section{Pembahasan}

\subsection{Ratio Legis Kewajiban Menjaga dan Menghormati Norma Agama, Adat Istiadat, Budaya dan Nilai-Nilai Yang Hidup dalam Masyarakat Bagi Wisatawan dalam Undang-Undang Kepariwisataan}

Pariwisata dapat merupakan bentuk imperialisme terselubung. Negara berkembang menjadi sasaran kunjungan wisatawan yang berasal dari negara maju, investasi dari negara yang bersangkutan dan bisnis yang dikuasai mereka termasuk cara dan bentuk pengembangan yang belum tentu sesuai dengan budaya setempat. (DPR RI, 2009)

Pariwisata juga rentan terhadap berbagai dampak negatif, mulai dari pemanfaatan secara tak bertanggung jawab untuk hal-hal yang bertentangan dengan norma dan nilai-nilai masyarakat Indonesia, sampai kepada penyelundupan barang atau manusia oleh wisatawan, bahkan penyelundupan/pencurian gen tetumbuhan, benda cagar budaya, pusaka nenek moyang. Bagian yang tak kalah penting adalah terjadinya pergeseran sistem nilai budaya yang ditimbulkan (intangible cultural aspect). (DPR RI, 2009)

Meskipun dimensi ekonomi sudah mencitrai pariwisata, namun pariwisata juga memiliki dimensi lain yang tak kalah penting yaitu dimensi sosial, budaya dan politik. Pada hakekatnya pariwisata merupakan bagian dari proses berbudaya, merupakan perilaku sosial manusia dalam rangka memenuhi kebutuhan psikososialnya. (DPR RI, 2009)
Pasal 28I (3) UUD NRI tahun 1945 menyebutkan identitas budaya dan hak masyarakat tradisional dihormati selaras dengan perkembangan zaman dan peradaban hal ini berarti bahwa pariwisata tidak berhak untuk memanfaatkan budaya tradisional semata-mata untuk kepentingan ekonomi keuntungan kelompok orang tertentu saja tanpa memberikan manfaat bagi masyarakat yang bersangkutan secara berkeadilan. (DPR RI, 2009)

Pasal 32 (1) UUD NRI tahun 1945 menyebutkan negara memajukan Kebudayaan Nasional Indonesia di tengah peradaban dunia dengan menjamin kebebasan masyarakat dalam memelihara dan mengembangkan kebudayaannya pariwisata yang dikelola dengan baik akan menjadi kendaraan untuk memajukan kebudayaan Indonesia juga pemanfaatan secara baik mendorong peningkatan kualitas seni dan budaya masyarakat karena apresiasi yang dirasakan oleh masyarakat dan pengembangan oleh pariwisata bagi pengembangan seni dan budaya itu sendiri. Secara ekonomi hal ini dapat diartikan dengan menginternalkan biaya pengembangan budaya dalam pariwisata.(DPR RI, 2009)

Indonesia perlu untuk mengambil sikap dalam pembangunan kepariwisataan sebelum terjerat dalam kurung lebih lanjut ke dalam ketergantungan kepada negara-negara maju. (DPR RI, 2009) Kebudayaan menjadi acuan bagi pemiliknya. Sebagai garis acuan masyarakat pemilik kebudayaan akan selalu berupaya memelihara dan melindungi serta menyeleksi masuknya unsurunsur kebudayaan asing di samping upaya untuk mengembangkan agar kebudayaan secara acuan selalu selaras dengan perkembangan lingkungannya dalam kaitannya dengan melakukan upayaupaya itu pemerintah atau negara sesuai pasal 32 UUD NRI tahun 1945 mendapat amanat untuk memajukan Kebudayaan Nasional Indonesia ditengah peradaban dunia dengan menjamin kebebasan masyarakat dalam memelihara dan mengembangkan nilai-nilai budayanya nama ini 


\section{Jurnal Cakrawala Hukum, Volume 12 No. 2 Agustus 2021}

ISSN PRINT 2356-4962 ISSN ONLINE 2598-6538

tentunya tidak semata-mata menjadi tanggung jawab pemerintah atau negara tetapi dilaksanakan bersama-sama dengan masyarakat pemiliknya. (DPR RI, 2009)

Kebudayaan sebagai buah usaha budidayanya rakyat Indonesia yang terdiri atas lebih dari 500 suku bangsa masing-masing memiliki kebudayaan yang berbeda dengan suku bangsa lain. Masing-masing memiliki ciri khas yang unik sehingga menjadi ciri penanda atau jati diri (identitas) yang dapat membedakan antara masyarakat suku bangsa satu dengan yang lain. Dalam kaitanya dengan kepariwisataan, keanekaragaman budaya bangsa itu menjadi salah satu daya tarik orang atau kelompok orang datang berkunjung untuk memperoleh pengalaman kesenangan dan kepuasan yang diperlukan sebagai pemenuhan kebutuhan hidup sebagai makhluk sosial. (DPR RI, 2009)

Pariwisata memiliki dampak positif maupun negatif, di bidang ekonomi, sosial dan budaya. Banyak referensi menunjukkan dampak positif pariwisata baik dari sisi ekonomi dan dampak negatif terhadap aspek sosial budaya. Namun demikian, seyogyanya kita dapat melihat secara lebih netral/imbang. Pariwisata memang terbukti telah memberikan kontribusi ekonomi yang luar biasa bagi banyak negara berkembang maupun negara maju, tetapi juga menciptakan ketergantungan kebocoran-kebocoran yang tak dapat dihindari. Banyak pariwisata di negara dunia ketiga dibangun dengan skenario negara memenuhi kebutuhan negara, dengan modal pembangunan pariwisata dari negara maju dan bisnis yang dikuasai oleh negara maju pula. (DPR RI, 2009)

Pada saat menghadapi krisis, seorang pejabat Bali sempat melontarkan pernyataan untuk membuka kesadaran kita semua bahwa pembangunan pariwisata di Bali tidak sama dengan pembangunan pariwisata untuk Bali. Banyak negara berkembang hanya menjadi lokasi pembangunan pariwisata tanpa mendapat manfaat yang sebanding dengan apa yang diterima oleh negara maju yang mem- bangun dan menikmati hasil pembangunannya. Sementara itu, masyarakat setempat meskipun mendapat manfaat namun tetap miskin dan makin tergantung. (DPR RI, 2009)

Pariwisata yang seringkali dilihat sebagai biang keladi dan memicu timbulnya berbagai kegiatan hiburan yang tak sesuai dengan norma masyarakat hendaknya disikapi dengan lebihnya netral. Prostitusi misalnya, sudah merupakan musuh masyarakat sejak dahulu, namun kita tidak dapat hanya menyalahkan pariwisata sebagai pemicu karena permasalahan tersebut perlu dilihat secara lebih holistik. Kita juga dapat mengetengahkan berbagai bukti bahwa masyarakat di tempat kunjungan wisata dapat belajar berbagai hal yang positif dan dapat memahami perbedaan budaya secara baik dalam kaitanya dengan komersialisasi budaya. (DPR RI, 2009)

Persoalan sebenarnya ialah apabila masyarakat atau negara tujuan wisata berada dalam posisi tawar tinggi maka kemungkinan menentukan sikap menjadi lebih tinggi. Toraja misalnya, pada masa jaya tahun 1990-an berani untuk mengambil sikap dan melarang wisatawan untuk keluar malam dan berpakaian yang menurut norma lokal dianggap tidak pas. Suatu bukti bahwa mereka tidak begitu saja membiarkan wisatawan berperilaku sesuka hati, sebaliknya mereka juga punya jati diri kuat yang melakukan kegiatan ritual pembakaran mayat yang mengundang wisatawan untuk ikut hadir dengan mengikuti tata cara lokal. (DPR RI, 2009)

Pemerintah sebagai pengawas, regulator dan fasilitator tehadap bidang pariwisata wajib menjaga beberapa aspek tersebut. Pemerintah juga berkewajiban menjaga dan menghormati norma agama, budaya, adat istiadat dan nilai-nilai yang hidup dalam masyarakat setempat agar tidak terpengaruh serta terganggu oleh wisatawan yang datang ketempat pariwisata. Secara empiris norma agama seharusnya wajib diimplementasikan keberbagai sector industry termasuk kepariwisataan. 


\section{Ratio legis kewajiban untuk menjaga dan menghormati norma agama berdasarkan Undang-Undang Kepariwisataan Dwi Aryanti Ramadhani, Aji Lukman Ibrahim, Rianda Dirkareshza}

Aspek selanjutnya yang tak luput untuk dikesampingkan dalam tata kelola kepariwisataan yang baik adalah adat istiadat. Ketaatan terhadap adat istiadat adalah wujud kepedulian terhadap para leluhur yang telah menciptakannya, mempertahankan kebersamaan, mengutamakan kedamaian antar warga, dan menghindari konflik internal. (Oematan, 2020)

Indonesia sebagai masyarakat majemuk mencerminkan adanya keragaman system nilai budaya yang dianut oleh berbagai kesatuan sosial. Kemajemukan tersebut dalam bidang agama, suku, maupun budaya. Masing-masing penganut system nilai cenderung kurang loyal terhadap system nilai secara keseluruhan, bahkan kurang memiliki kesadaran untuk memahami satu sama lain. Maurice Duverger mengatakan dalam langkah perkembangan menuju integrasi itu merupakan suatu usaha untuk membangun interdependensi yang lebih erat antara bagian-bagian atau unsur-unsur dari masyarakat, sehingga dapat tercipta suatu keadaan yang harmonis yang memungkinkan terjalinnya kerjasama dalam rangka mencapai tujuan yang telah disepakati bersama.(Suwarno, 2017)

Salah satu hal yang harus dilakukan Pemerintah dalam mengembangkan sebuah kawasan Pariwisata adalah membuat kebijakan pariwisata. Secara sederhana kebijakan pariwisata dapat diartikan sebagai, kebijakan yang mengidentifikasi sasaran-sasaran serta tujuan-tujuan yang membantu agent dalam proses perencanaan industry pariwisata.(Fennell, 2003)

Pemerintah memberikan penghormatan terhadap identitas budaya dan hak-hak masyarakat tradisional.Budaya lokal adalah salahsatu daya tarik pariwisata. Pelestarian dan pengembangan budaya akan meningkatkan kunjungan wisatawan yang secara langsung akan meningkatkan pendapatan pengusaha dan pendapatan masyarakat. (Menteri Kebudayaan dan Pariwisata, 2004) Oleh karena itu, pengusaha pariwisata mempunyai kewajiban peningkatan kapasitas budaya masya- rakat local serta menjaga budaya agar tidak terafiliasi dengan budaya-budaya yang dibawa oleh wisatawan domestic maupun manca negara.

\subsection{Sanksi Terhadap Wisatawan Yang Melanggar Norma Agama, Adat Istiadat, Budaya, Dan Nilai-Nilai Yang Hidup Dalam Masyarakat Ditempat Wisata}

Penulis berhasil mewawancarai bapak Nurdin kepala Desa Kadubungbang, Kecamatan Cimanuk, Kabupaten Pandeglang, Banten. Di mana lokasi tersebut mempunyai wisata alam Cikoromoy dan Batu Qur'an. Berdasarkan hasil wawancara di desa Kadubungbang terdapat aturan mengenai wisata halal yang tertuang dalam Peraturan Desa (Perdes). (Nurdin Kepala Desa Kadubungbang, 2020)

Lembaga yang terkait dalam penetapan pariwisata halal adalah Balai Desa, Lembaga Pemberdayaan Masyarakat (LPM), Badan Permusyawaratan Desa (BPD) dan Organisasi Masyarakat (ormas). Evaluasi penerapan pariwisata halal 5 tahun terakhir yang dilakukan oleh Balai Desa telah dinilai baik dan efektif. Namun demikian, terdapat kendala yaitu adanya pungutan liar (pungli) dari oknum masyarakat setempat dan menjadi keluhan para wisatawan yang berkunjung. Hal demikian telah menjadi konsen dari LPM untuk menindak para pelaku pungli. (Nurdin Kepala Desa Kadubungbang, 2020)

Berdasarkan hasil wawancara dengan kepala Desa Kadubungbang, sanksi yang terhadap wisatawan yang melanggar norma agama, adat istiadat, budaya dan nilai-nilai masyarakat tertuang dalam Perdes setempat. Sanksi yang diterapkan berupa teguran. Selanjutnya Nurdin mengungkapkan bahwa pernah terjadi kasus wisatawan asing yang datang berwisata dan menginap di sebuah villa di desa Kadubungbang, turis tersebut membuat sebuah pesta yang cukup membuat ketidaknyamanan di lingkungan masyarakat. (Nurdin Kepala Desa Kadubungbang, 2020) 


\section{Jurnal Cakrawala Hukum, Volume 12 No. 2 Agustus 2021 \\ ISSN PRINT 2356-4962 ISSN ONLINE 2598-6538}

Pesta tersebut dinilai tidak sesuai dengan norma agama, adat istiadat, budaya dan nilai-nilai masyarakat tertuang dalam Perdes. Sehingga turis tersebut didatangi oleh warga dan kepala desa setempat, kemudian diberikan sanksi berupa teguran untuk segera menghentikan pesta yang membuat kegaduhan di lingkungan masyarakat Kadubungbang. (Nurdin Kepala Desa Kadubungbang, 2020)

Berdasarkan uraian di atas, menurut penulis sanksi yang diatur dalam Perdes Kadubungbang belum tegas dan memberikan efek jera bagi wisatawan agar menaanti/menghormati norma agama, adat istiadat, budaya dan nilai-nilai masyarakat. Sanksi yang seharusnya diterapkan di masa mendatang sebaiknya dapat memberikan keuntungan bagi masyarakat setempat yang terganggu kenyamanannya.

Dalam hal ini, sanksi tersebut dapat berupa pertama, denda yang akan menambah kas Desa. Dengan demikian desa akan mendapatkan ganti kerugian akibat terganggunya kenyamanan yang diakbibatakan oleh ulah wisatawan yang melanggar. Kedua, pengembalian keadaan seperti sebelum pelanggaran terjadi. Dengan sanksi ini lingkungan masyarakat/wisata yang terganggu/rusak dapat kembali seperti semula dan tidak membuat kerusakan tersebut menjadi beban marayakat/ pengelola tempat wisata untuk memperbaikinya. Ketiga, membuat permintaan maaf secara terbuka di depan Kepala Desa, Tokoh Agama, Tokoh Masyarakat, Tokoh Adat dan masyarakat setempat disertai surat pernyataan tidak akan mengulangi kembali kesalahan tersebut.

\section{Simpulan}

Hasil penelitian menunjukkan bahwa ratio legis kewajiban untuk menjaga dan menghormati norma agama, adat istiadat, budaya, dan nilai-nilai yang hidup dalam masyarakat bagi wisatawan adalah agar budaya setempat tidak hilang akibat terkikis budaya asing yang dibawa oleh para wisatawan.

Kemudaian sanksi yang diterapkan terhadap wisatawan yang melanggar hanya berupa teguran kurang sepadan dengan kerugian yang ditimbulkan. Sehingga di masa mendatang Perdes Kadubungbang seharusnya sanksi berupa denda, pengembalian keadaan seperti sebelum pelanggaran terjadi, dan membuat permintaan maaf secara terbuka dan membuat surat pernyataan.

\section{Daftar pustaka}

Antara. 2018. Akibat Tsunami, Pariwisata Pandeglang dan Serang Lumpuh. Retrieved from Tempo website: https://bisnis.tempo.co/read/1159358/ akibat-tsunam.

Arnani, M. 2018. 8 Fakta Tsunami Selat Sunda, Pemicu Kejadian hingga Korban Jiwa. Retrieved from https://regional.kompas.com/read/2018/12/ 24/114513.

Banten, P. D. P. (n.d.). Geografi Provinsi Banten. Retrieved from https://bantenprov.go.id/profil-provinsi/ geografi.

Banten, P. D. P. 2020. Tentang Provinsi Banten. Retrieved from https://www.bantenprov.go.id/profilprovinsi/profi.

Bappenas. 2005. Visi dan Arah Pembangunan Jangka Panjang (PJP) tahun 2005-2025. Badan Perencanaan Pembangunan Nasional, 142. Retrieved from https:/ /www.bappenas.go.id/files/1814/2057/0437/ RPJP_2005-2025.pdf.

Defianti, I. 2018. Tsunami Selat Sunda, Ini 10 Kecamatan Terparah di Pandeglang. Retrieved from Liputan6.Com website: https:// www.liputan6.com/news/read/3855284/tsunami-selat-sunda-ini-10-kecamatan-terparah-dipandeglang.

Depbudpar, 2004. Peraturan Menteri Kebudayaan dan Pariwisata Nomor km.67/um.001/MKP/2004 Tentang Pedoman Umum Pengembangan Pariwisata di Pulau-Pulau Kecil. Menteri Kebudayaan dan Pariwisata. Jakarta. 


\section{Ratio legis kewajiban untuk menjaga dan menghormati norma agama berdasarkan Undang-Undang Kepariwisataan}

Dwi Aryanti Ramadhani, Aji Lukman Ibrahim, Rianda Dirkareshza

Devika, M., Mulyono, G. P., \& Nahuddin, Y. E., 2020. Penegakan Protokol Kesehatan dalam Penyelenggaraan Pilkada Serentak di Tengah Pandemi Covid I9. In Conference on Law and Social Studies (Vol. 1, No. 1, pp.1-15).

Djuwita, D., Purnamasari, D., Studi, P., Syariah, P., Iain, F., \& Nurjati, S. 2017. Dampak Keberadaan Pariwisata Religi terhadap Perkembangan Ekonomi Masyarakat Cirebon. Al-Amwal, Volume 9, No. 1 Tahun 2017, 9(1), 97-110.

DPR RI. 2009. Naskah akademis Rancangan Undang-undang Tentang Kepariwisataan. 1-30.

Fennell, David A., and R. K. D. 2003. Ecotourism policy and planning. CABI.

Hamzana, A. A. 2018. Pelaksanaan Standarisasi Pelayanan Pariwisata Halal dalam Pengembangan Pariwisata di Nusa Tenggara Barat. Pena Justisia: Media Komunikasi Dan Kajian Hukum, 17(2), 1-16. https://doi.org/10.31941/ pj.v17i2.545.

Indonesia, R. Undang - Undang Nomo 10 Tahun 2009 Tentang Kepariwisataan.

Kristiana, Y., \& Stephanie Thedora M. 2016. Strategi Upaya Pengembangan Pariwisata Berkelanjutan Agrowisata Berbasis Masyarakat Kampung Domba Terpadu Juhut, Provinsi Banten. Jurnal Ilmiah Widya, 3(3), 1-7.

Kurniansah, R. 2018. Kajian Potensi Pariwisata Perkotaan (Urban Tourism) Sebagai Daya Tarik Wisata Kota Mataram Ntb. Media Bina Ilmiah, 13(2), 925-930. https://doi.org/https://doi.org/ 10.33758/mbi.v13i2.158.

Menteri Kebudayaan dan Pariwisata. Peraturan Menteri Kebudayaan dan Pariwisata Nomor/ : km.67/um.001/ MKP/2004 Tentang Pedoman Umum Pengembangan Pariwisata di Pulau-Pulau Kecil. Menteri Kebudayaan dan Pariwisata.

Mufida, A. 2019. Agama dan Kearifan Lokal Dalam Pengembangan Integrasi Sosial. 39(2), 183-196.
Mukhroman, I., \& Gumelar, R. G. 2013. Perencanaan Strategi Humas Pemprov Banten Pasca Ditetapkannya Kek Pariwisata Tanjung Lesung, Pandeglang, Banten. Jurnal Kajian Komunikasi, 1(2), 206-218. https://doi.org/10.24198/jkk.vol1n2.10.

Nurdin Kepala Desa Kadubungbang. 2020. Wawancara dengan Lurah Desa Kadubungbang - Wisata Alam Cikoromoy \& Batu Qur'an. Pandeglang.

Oematan, R. (2020). Representasibudaya nusa tenggara timur dalam kumpulan cerpen. Mataram.

Pandeglang, P. D. K. (209 C.E.). Kabupaten Pandeglang. Retrieved from https://id.wikipedia.org/wiki/ Kabupaten_Pandeglang.

Pandeglang, P. D. K. 2019. Profil Kabupaten Pandeglang. Retrieved from http://www.kelair.bppt.go.id/ sitpapdg/profilkabpdg.

Pemerintah Daerah Provinsi Banten. 2020. Gambar Peta Pariwisata Provinsi Banten. Retrieved from https:/ /dispar.bantenprov.go.id/home.

Sayogi, K. W., \& Dermatoto, A. 2009. Pengembangan Pariwisata Bahari. Journal of Development and Social Change, 1(1), 9-17.

Suwarno. 2017. Sistem Sosial Budaya Indonesia. Bandar Lampung.

Yanti, N., \& Hadya, R. 2018. Kontribusi Sektor Pariwisata Terhadap Peningkatan Pad Kota Padang. Jurnal Benefita, 3(3), 370. https://doi.org/10.22216/ jbe.v3i3.3692.

Undang-Undang Dasar Negara Republik Indonesia Tahun 1945.

Republik Indonesia, Undang-Undang Pariwisata, Undang-Undang Nomor 10 tahun 2009 Lembaran Negara Republik Indonesia Tahun 2009Nomor 11, Tambahan Lembaran Negara Republik Indo-nesia Nomor 4966. 